\title{
Enhanced Reactivity of Water Clusters towards Oxidation in Water/Acetonitrile Mixtures
}

\author{
Jonnathan C. Hidalgo-Acosta, ${ }^{[a]}$ Micheál D. Scanlon, ${ }^{[b]}$ Manuel A. Méndez, ${ }^{[a]}$ Pekka Peljo, ${ }^{[a]}$ \\ Marcin Opallo, ${ }^{[\mathrm{c}]}$ and Hubert H. Girault*[a] \\ Dedicated to Professor Christian Amatore on occasion of his 65th birthday
}

\begin{abstract}
The water oxidation process in acidified water/acetonitrile mixtures was studied by cyclic voltammetry using fluorinated tin oxide (FTO) electrodes modified layer-by-layer with deposited bilayers of positively charged poly(diallyldimethylammonium chloride) (PDDA) polymer and negatively charged citrate-stabilized iridium oxide $\left(\mathrm{IrO}_{2}\right)$ nanoparticles. The voltammetric profiles obtained at high water contents resemble those in aqueous media and remain approximately unchanged. However, as the water content decreases below a water mole fraction $\left(\mathrm{XH}_{2} \mathrm{O}\right)$ of 0.6 , a tipping point is reached and the onset potential for water oxidation gradually decreases. This reflects an enhanced reactivity, and therefore lower overpotential, of water molecules towards oxidation in water/acetonitrile mixtures. These lower kinetic barriers towards water oxidation are rationalized based on the degradation of the hydrogen bond network upon the formation of water/acetonitrile mixtures. Thus, as the ice-like structure of neat water transitions to clusters and low-bonded oligomers, these water molecules in more "free" states exhibit an enhanced susceptibility to water oxidation.
\end{abstract}

Water is the ultimate source of electrons in idealized artificial photosynthetic schemes. These electrons may be released during water splitting, preferably utilizing solar energy in a photoelectrochemical arrangement, and used to produce small molecules such as molecular hydrogen $\left(\mathrm{H}_{2}\right)$, a solar fuel. Importantly, this route to $\mathrm{H}_{2}$ avoids the generation of greenhouse gases. ${ }^{[1]}$ Since the $\mathrm{H}_{2}$ evolution reaction (HER) is much less

[a] J. C. Hidalgo-Acosta, Dr. M. A. Méndez, Dr. P. Peljo, Prof. H. H. Girault Laboratoire O'Electrochimie Physique et Analytique

Ecole Polytechnique Fédérale de Lausanne, EPFL Valais Wallis Case Postale 440, 1951 Sion (Switzerland)

E-mail: Hubert.girault@epfl.ch

[b] Dr. M. D. Scanlon

Department of Chemistry

The Tyndall National Institute and

the Analytical \& Biological Chemistry Research Facility (ABCRF) University College Cork

Western Road, Cork (Ireland)

[c] Prof. M. Opallo

Institute of Physical Chemistry

Polish Academy of Sciences

Kasprazaka 44/52, 01-224 Warszawa (Poland)

$\square$ Supporting Information and the ORCID identification number(s) for the

(iD author(s) of this article can be found under http://dx.doi.org/10.1002/ celc. 201600190 .

This is an invited contribution for the Christian Amatore Festschrift energy-demanding than the water oxidation reaction (WOR), the later process is considered the limiting step in the overall water splitting scheme, requiring the use of a catalyst. Much effort has been devoted to the development of such catalysts that can perform the WOR for long time periods and at moderate overpotentials. ${ }^{[2]}$ However, little attention has been paid to the influence of the media within which the reaction takes place as a route to enhance the reactivity of water.

The physciochemical properties of water are expected to change in the presence of ions or organic molecules. Such changes can be advantageous as they can be translated into modifications of reactivity. For instance, Markovic et al. reported that the non-covalent interaction between ions in alkaline solutions and the oxygenated species absorbed on the surface of $\mathrm{Ir}, \mathrm{Ru}$ and $\mathrm{Ru}_{0.5} \mathrm{Ir}_{0.5}$ electrodes, play an important role in the hydrogen evolution reaction (HER), hydrogen oxidation reaction (HOR) and oxygen evolution reaction (OER). ${ }^{[3]}$ Particularly, the reactivity towards the HER increases in the order $\mathrm{Ba}^{2+}>$ $\mathrm{Li}^{+}>\mathrm{K}^{+}$. This trend is explained based on the higher ability of absorbed water to be dissociated into $\mathrm{H}_{\text {ad }}$ and ${ }^{*} \mathrm{OH}$, upon interaction with ions of higher specific charge density. Similar effects have been reported by Deng and co-workers, suggesting that the increased acidity of the water in the solvation shell of $\mathrm{Li}^{+}$can be used to facilitate both the oxygen reduction reaction (ORR) and HER. ${ }^{[4]}$

The use of co-solvents has also proven to be a good approach to modify the reactivity of water molecules. In this regard, Meyer and co-workers reported that the rate of the WOR at nanostructured indium tin oxide (ITO) electrodes modified with the molecular catalysts $\left[\mathrm{Ru}(\mathrm{Mebimpy})(\mathrm{bpy})\left(\mathrm{OH}_{2}\right)\right]^{2+}$ (Mebimpy =2,6-bis(1-methylbenzimidazol-2-yl)pyridine; bpy = $2,2^{\prime}$-bipyridine $)^{[5]}$ and $\left[\mathrm{Fe}^{\text {III }}(\mathrm{dpaq})\left(\mathrm{H}_{2} \mathrm{O}\right)\right]^{2+} \quad(\mathrm{dpaq}=2$-[bis $($ pyridine-2-ylmethyl)] amino- $N$-quinolin-8-yl-acetamido) was enhanced when mixtures of water and propylene carbonate were used as a reaction medium instead of neat water. ${ }^{[6]}$ In a series of publications, Bond and co-workers also highlighted the use of ionic liquids as media to facilitate the WOR. The exceptional reactivity was attributed to the modification of the structure of molecular water in ionic liquids where it may exist in a unique "free" state that excludes self-aggregation via hydrogen-bonding. ${ }^{[7]}$

Recently, we reported that the kinetics of the WOR, with $\left[\mathrm{Ru}(\mathrm{bpy})_{3}\right]^{3+}$ as the electron acceptor and $\mathrm{IrO}_{2}$ nanoparticles (NPs) as the catalyst, was dependent on the water content when the reaction takes place in water/acetonitrile (ACN) mixtures. ${ }^{[8]}$ It is well-known that the structure of water in water/ 
ACN mixtures is dependent on the ratio between the two solvents, ${ }^{\left[{ }^{[9]}\right.}$ or the water mole fraction $\left(\mathrm{XH}_{2} \mathrm{O}\right)$. The ice-like structure of water is predominant at high water contents. However, as the water content decreases below $\mathrm{XH}_{2} \mathrm{O} \leq 0.8$, the hydrogen bond structure degrades and water is present preferentially as clusters. In comparison to pure water, our kinetic measurements indicated that water molecules in these clusters show a markedly enhanced susceptibly to oxidation. The WOR exhibited bimolecular kinetics, first order with respect to the concentration of $\mathrm{IrO}_{2} \mathrm{NPs}$ and the concentration of oxidant. Notably, the second-order rate constant depended on the water content, showing a maximum at approximately equimolar proportions $\left(\approx 25 \% \mathrm{H}_{2} \mathrm{O}(\mathrm{v} / \mathrm{v})\right)$, when both water and ACN clusters co-exist in the mixture. The present communication rationalizes the changes in the reactivity of water molecules in water/ ACN mixtures of various compositions by demonstrating that the onset potential for the WOR at an electrode surface modified with $\mathrm{IrO}_{2} \mathrm{NP}$ catalyst shifts as $\mathrm{XH}_{2} \mathrm{O}$ is varied. To achieve this, we utilized fluorinated tin oxide (FTO) electrodes modified sequentially layer-by-layer with the positively charged polymer poly(diallydimethylammonium chloride) (PDDA) and negatively charged citrate-stabilized $\mathrm{IrO}_{2} \mathrm{NPs}$ (see Figure 1). In a separate

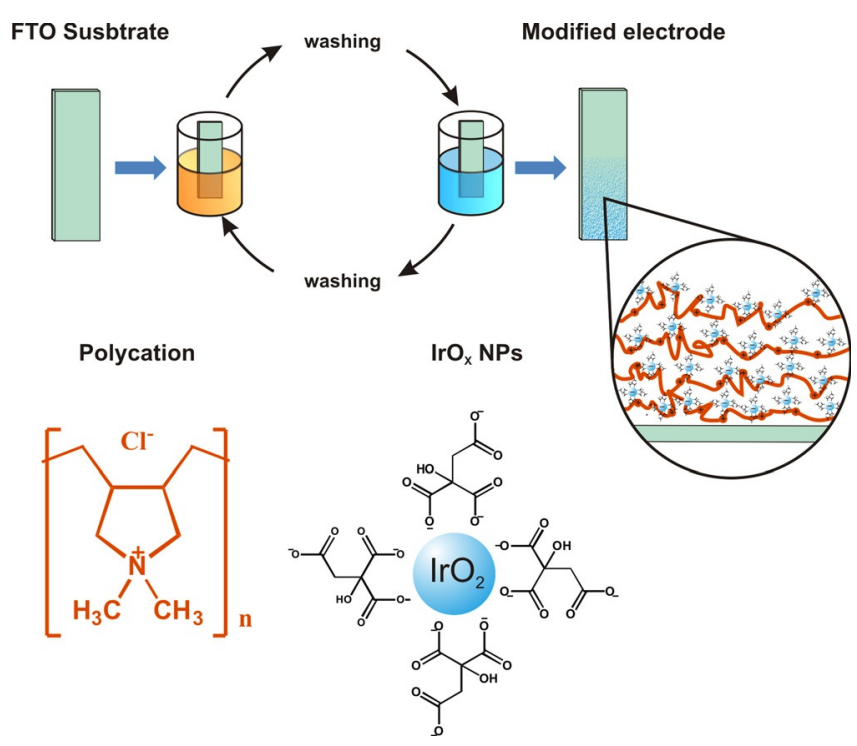

Figure 1. Layer-by-layer deposition of $\mathrm{IrO}_{2} / \mathrm{PDDA}$ bilayers on the FTO electrode surface.

study, we clearly demonstrated the electrocatalysis of the WOR in aqueous media using these layer-by-layer modified FTO electrodes that exhibited good operational stability, remaining active over a wide pH-range. ${ }^{[10]}$ Herein, these electrodes are utilized as a platform to study the electrocatalysis of the WOR in water/ACN mixtures. The goal is to provide a clear correlation between the enhanced kinetics of the WOR in water/ACN mixtures, demonstrated previously, ${ }^{[8]}$ and the underlying thermodynamics that facilitates this kinetic enhancement.

The catalytic oxidation of water in water/ACN mixtures by $\left[\mathrm{Ru}(\mathrm{bpy})_{3}\right]^{3+}$ is dependent on the acid-base properties of the media at a fixed water content $(10 \%(\mathrm{v} / \mathrm{v})){ }^{[8]}$ The reaction rates using $4.3 \mathrm{~mm} \mathrm{NaHCO} / \mathrm{Na}_{2} \mathrm{SiF}_{6}$ buffer as the acidic regulator exceeded by two orders of magnitude those found in $20 \mathrm{~mm}$ $\mathrm{HClO}_{4}{ }^{[8]}$ Thus, in an effort to determine the second-order reaction constant as accurately as possible, $20 \mathrm{~mm} \mathrm{HClO}_{4}$ was chosen in preference to $\mathrm{NaHCO}_{3} / \mathrm{Na}_{2} \mathrm{SiF}_{6}$ as its slower base rate of catalysis permitted far greater temporal resolution during the kinetic study. ${ }^{[8]}$ Herein, $\mathrm{HClO}_{4}$ was chosen 1 ) to have a direct comparison with the kinetic experiments previously reported, ${ }^{[8]}$ 2) as $\mathrm{HClO}_{4}$ allows experiments to be performed without the addition of other supporting electrolytes, and 3 ) as the $1 \mathrm{rO}_{2} /$ PDDA bilayers on the FTO electrode exhibit optimal stability under these acidic conditions. ${ }^{[10]}$

A key consideration in the experimental design was the methodology to calibrate the reference electrode. A detailed study of the effect of varying water content on the WOR onset potential for a water/non-aqueous solvent requires the use of a universal scale to compare potentials between individual experiments. This is easily accomplished in pure aqueous solutions by the use of universally accepted references such as the saturated calomel electrode (SCE) or $\mathrm{Ag} / \mathrm{AgCl}$ electrode, both of whose potentials versus the standard hydrogen electrode (SHE) are well-known and stable over time. Cyclic voltammetry experiments herein, however, were carried out in the presence of significant quantities of organic solvent and the use of the aforementioned references in organic solvents inevitably includes unknown liquid junction potentials. A typical approach to circumvent this difficulty is the use of an internal redox active reference molecule such as ferrocene. However, as the composition of the solvent changes, the hydration properties of both the reduced and oxidized species are also modified. ${ }^{[1]}$ Therefore, the potential of the internal reference itself on the universal scale is also expected to change. The calculation of those potentials via thermodynamic cycles is also problematic due to the large body of thermodynamic quantities required.

Herein, two independent references, $\mathrm{Ru}\left(\mathrm{NH}_{3}\right)_{6} \mathrm{Cl}_{3}$ and the $\mathrm{IrO}_{2} \mathrm{NP} \operatorname{Ir}(\mathrm{III}) / \mathrm{Ir}(\mathrm{IV})$ redox transition, were used to have a qualitative idea of the reactivity of water in the water/ACN mixtures. In this regard, after each experiment, the potential window was calibrated by the addition of $\approx 80 \mu \mathrm{M} R u\left(\mathrm{NH}_{3}\right)_{6} \mathrm{Cl}_{3}$. This molecule was used as an internal reference due to the suitability of its redox potential, discussed below, and good solubility across the range of $\mathrm{XH}_{2} \mathrm{O}$ values studied. A cyclic voltammogram (CV) of the $\mathrm{IrO}_{2} / \mathrm{PDDA}$ modified FTO electrode in water/ ACN mixtures containing $20 \mathrm{~mm} \mathrm{HClO}_{4}$ and $80 \mu \mathrm{M} \mathrm{Ru}\left(\mathrm{NH}_{3}\right)_{6} \mathrm{Cl}_{3}$ is shown in Figure 2. Clearly, the redox couple associated with $\mathrm{Ru}\left(\mathrm{NH}_{3}\right)_{6} \mathrm{Cl}_{3}$ is well-separated from the redox processes of the $\mathrm{IrO}_{2} \mathrm{NPs}$, allowing a precise determination of the potential. CVs of the $\mathrm{IO}_{2} /$ PDDA-modified FTO electrodes as a function of $\mathrm{XH}_{2} \mathrm{O}$ in water/ACN mixtures are shown in Figures $3 \mathrm{~A}, \mathrm{~B}$. The 5th CV cycle was chosen for comparison due to the substantial changes in the observed voltammetry, associated with the relaxation processes of the film that take place during the first few CV cycles. This is especially the case at low water contents, where the medium is substantially different to that used during layer-by-layer deposition.

The CVs were taken at low potentials because the stability of the $\mathrm{IrO}_{2} / \mathrm{PDDA}$ modified FTO electrode at higher potentials 


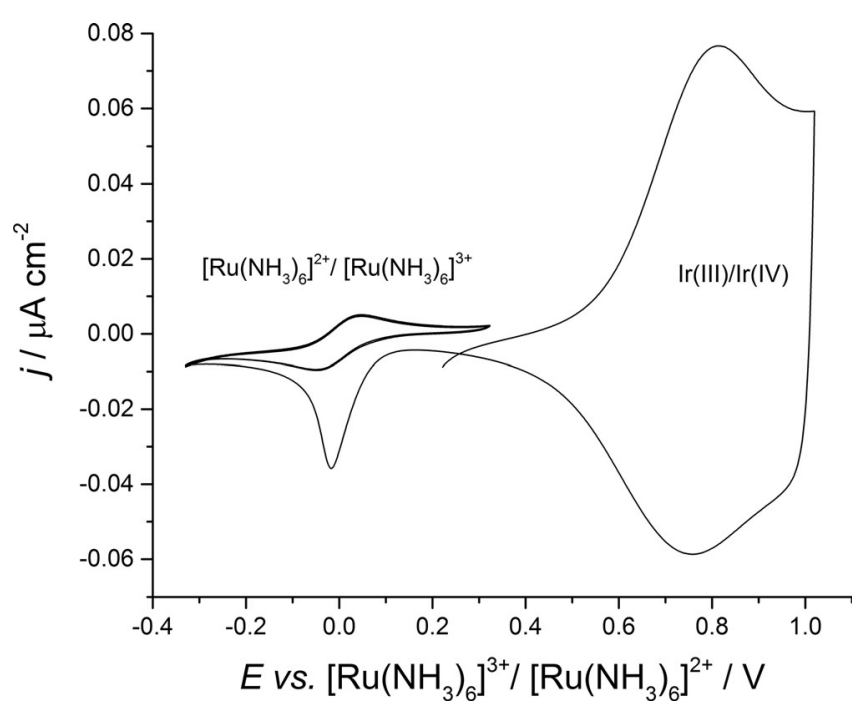

Figure 2. Cyclic voltammogram of an FTO electrode modified with eight $\mathrm{IrO}_{2} /$ PDDA NP bilayers in the presence of $\approx 80 \mu \mathrm{M} \mathrm{Ru}\left(\mathrm{NH}_{3}\right)_{6} \mathrm{Cl}_{3}$. The supporting electrolyte was $20 \mathrm{~mm} \mathrm{HClO}_{4}$ in a water/ACN mixture $\left(35 \%(v / v) \mathrm{H}_{2} \mathrm{O}\right)$.

is substantially reduced in ACN containing solutions. This loss of stability, which is marginal at the working conditions employed (low potentials), most likely takes place due to the swelling of the polymer and the breakdown of the electrostatic interactions binding the layers together on the electrode surface. Noticeably, all CVs in Figures $3 \mathrm{~A}, \mathrm{~B}$ resemble those obtained previously in acidic aqueous media exhibiting $\operatorname{Ir}(\mathrm{III})$ $\operatorname{Ir}(\mathrm{III}) / \operatorname{Ir}(\mathrm{IV})-\operatorname{Ir}(\mathrm{IV})$ and $\operatorname{Ir}(\mathrm{IV})-\operatorname{Ir}(\mathrm{IV}) / \operatorname{Ir}(\mathrm{IV})-\operatorname{Ir}(\mathrm{V})$ redox transitions at $0.78 \mathrm{~V}$ and $1.07 \mathrm{~V}$, respectively, ${ }^{[10,12]}$ and the onset potential for the WOR in the range 1.17-1.32 V. The formation of oxygen upon oxidation at potentials beyond this value was confirmed by gas chromatography (Supporting Information). A closer inspection of the CVs in Figure $3 \mathrm{~A}$ (inset) reveals that at high water content $\left(\mathrm{XH}_{2} \mathrm{O} \geq 0.6\right)$, the voltammetry remains practically unaffected. However, as the water content decreases (Figure $3 \mathrm{~B}$ ), the onset potential for the WOR is shifted towards more negative potentials (i.e., to lower overpotentials), while the potential of the $\operatorname{Ir}(\mathrm{III}) / \mathrm{Ir}(\mathrm{IV})$ redox transition increases significantly.

The onset potentials for the WOR as a function of $\mathrm{XH}_{2} \mathrm{O}$ or \% water $(v / v)$ are summarized in Figure $3 \mathrm{C}$ and Table 1 , refer-

\begin{tabular}{|c|c|c|}
\hline $\begin{array}{l}\text { Water mole fraction } \\
\left(\mathrm{XH}_{2} \mathrm{O}\right)\end{array}$ & $\begin{array}{l}\left.E \text { vs. } \mathrm{Ru}\left(\mathrm{NH}_{3}\right)_{6}\right]^{3+} /\left[\mathrm{Ru}\left(\mathrm{NH}_{3}\right)_{6}\right]^{2+} \\
{[\mathrm{V}]}\end{array}$ & $\begin{array}{l}E \text { vs. } \operatorname{Ir}(\mathrm{IV}) / \operatorname{Ir}(\mathrm{III}) \\
{[\mathrm{V}]}\end{array}$ \\
\hline 0.244 & 1.187 & 0.341 \\
\hline 0.338 & 1.192 & 0.354 \\
\hline 0.491 & 1.240 & 0.426 \\
\hline 0.610 & 1.287 & 0.521 \\
\hline 0.744 & 1.300 & 0.524 \\
\hline 0.871 & 1.304 & 0.518 \\
\hline 0.921 & 1.303 & 0.519 \\
\hline 0.963 & 1.313 & 0.518 \\
\hline
\end{tabular}
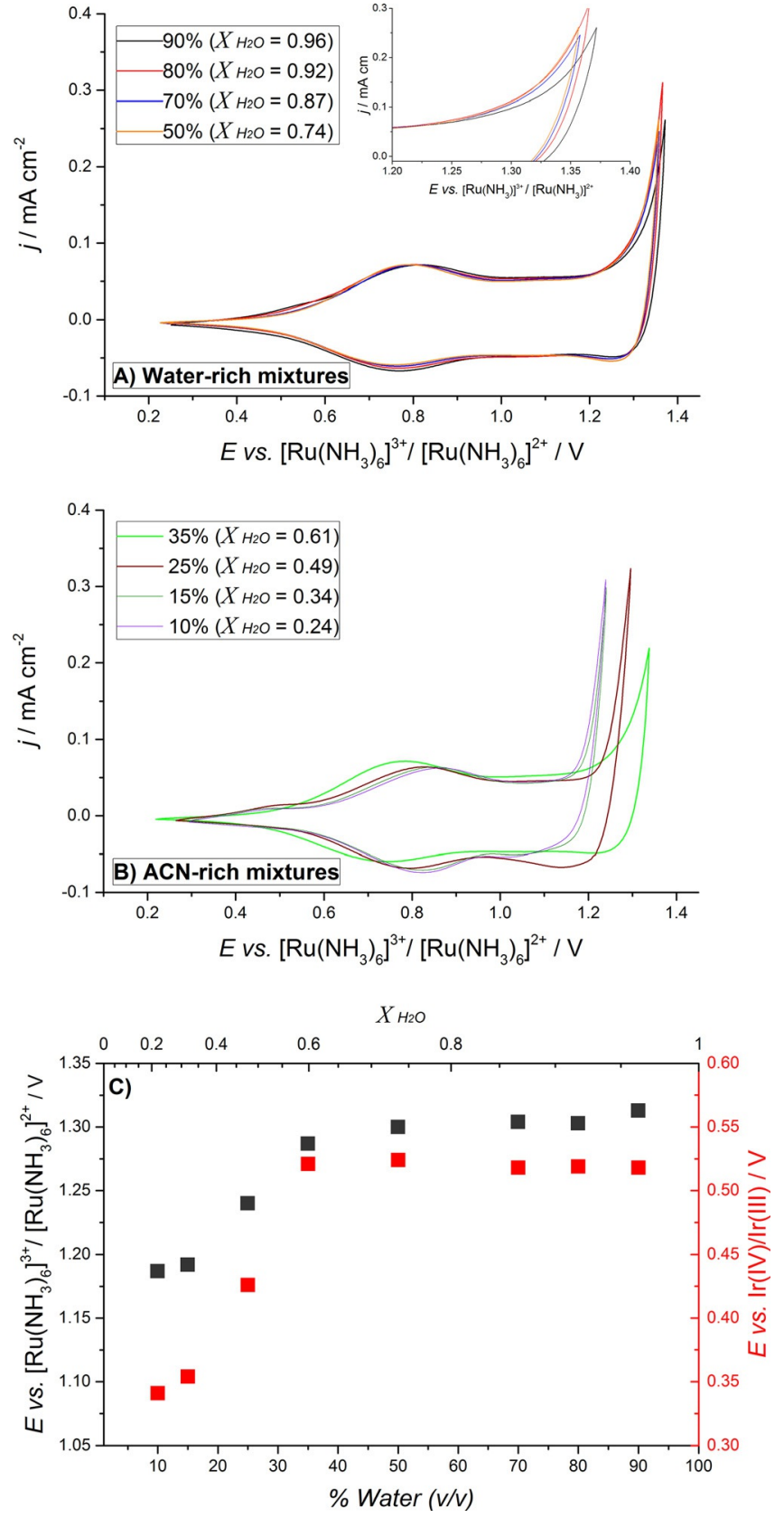

Figure 3. $A, B) C V$ s of the $1 \mathrm{rO}_{2} / \mathrm{PDDA}$ modified $\mathrm{FTO}$ electrode in water/ACN mixtures as a function of water mole fraction $\left(\mathrm{XH}_{2} \mathrm{O}\right)$. C) Onset potentials for the WOR in water/ACN mixtures represented on two different potential scales: black squares, versus $\left[\mathrm{Ru}\left(\mathrm{NH}_{3}\right)_{6}\right]^{3+} /\left[\mathrm{Ru}\left(\mathrm{NH}_{3}\right)_{6}\right]^{2+}$; red squares, versus $\operatorname{Ir}(\mathrm{IV}) / \mathrm{Ir}(\mathrm{III})$

enced both against the scale calibrated with the $\left[\mathrm{Ru}\left(\mathrm{NH}_{3}\right)_{6}\right]^{2+}$ $/\left[\mathrm{Ru}\left(\mathrm{NH}_{3}\right)_{6}\right]^{3+}$ redox couple and also versus the $\operatorname{Ir}(\mathrm{III}) / \mathrm{Ir}(\mathrm{IV})$ redox transitions of the $\mathrm{IrO}_{2} \mathrm{NPs}$. In both cases, the tendency is almost the same. A relatively constant onset potential for the WOR is observed as the water content decreases from $X \mathrm{H}_{2} \mathrm{O}=$ 0.9 to $X \mathrm{H}_{2} \mathrm{O}=0.6$. Subsequently, a sharp decrease in the onset potential is observed when $X \mathrm{H}_{2} \mathrm{O} \leq 0.6$. Such changes cannot only be attributed to variations of the potential of the internal $\left[\mathrm{Ru}\left(\mathrm{NH}_{3}\right)_{6}\right]^{2+} /\left[\mathrm{Ru}\left(\mathrm{NH}_{3}\right)_{6}\right]^{3+}$ reference electrode on the standard hydrogen scale. Indeed, the fact that the onset potential mea- 
sured with respect to the $\operatorname{Ir}(\mathrm{III}) / \mathrm{Ir}(\mathrm{IV})$ redox transition follows the same trend is a good indication that the changes in the onset potential are mostly related to the change in the thermodynamics or kinetics of the WOR as a function of $\mathrm{XH}_{2} \mathrm{O}$, rather than artifacts due to the potential scale calibration.

The evaluation of the Nernst potential for the oxygen/water couple by taking into account the changes in the activities of water, $\mathrm{HClO}_{4}$ and $\mathrm{O}_{2}$ upon increasing the mole fraction of $\mathrm{ACN}$ actually predict an increase in the thermodynamic potential for WOR (see Supporting Information for more details). Hence, the decrease in the onset potential shown in the Figure $3 \mathrm{C}$ for ACN-rich solutions must be due to a favorable kinetic effect in the WOR rather than a lowering of the thermodynamic barriers.

X-ray diffraction and infra-red (IR) spectroscopy studies of water/ACN mixtures by Takamuku et al. revealed that the strong hydrogen-bond network gradually degrades upon the introduction of $A C N .^{[9 e]}$ This process leads to the formation of water clusters or micro-heterogeneities at $0.4 \leq X \mathrm{H}_{2} \mathrm{O} \leq 0.8$ and, finally, low bonded trimers and tetramers when the amount of water decreases below $\mathrm{XH}_{2} \mathrm{O} \approx 0.4$. An increase in the frequency of the $\mathrm{O}-\mathrm{H}$ vibration with decreasing $\mathrm{XH}_{2} \mathrm{O}$ was observed by Takamuku et al. and is used as an indication of the strength of the hydrogen bonding. Those changes in the organization of the water molecules directly influence their reactivity, as described previously. ${ }^{[8]}$ For instance, the trend in the variation of the strength of the hydrogen bonding as a function of $\mathrm{XH}_{2} \mathrm{O}$ was mirrored by our previous findings, where the secondorder rate constant for water oxidation using the oxidant $\left[\mathrm{Ru}^{\mathrm{III}}(\mathrm{bpy})_{3}\right]^{3+}$ and catalyzed by $\mathrm{IrO}_{2} \mathrm{NPs}$, increased progressively with decreasing $X_{2} \mathrm{O}$ in the region $0.4 \leq X \mathrm{H}_{2} \mathrm{O} \leq 0.8$. Indeed, the second-order constant in this region exceeded that at high water contents, where the water is present as an extended hydrogen-bonded structure, by more than a factor of three. Importantly, the changes in the kinetics of the WOR we determined previously correlate well with the reduced kinetic barriers towards water oxidation observed here below $X \mathrm{H}_{2} \mathrm{O} \approx 0.6$ (see Figure $3 \mathrm{C}$ ). The later value for mixtures containing $X_{2} \mathrm{O}$ $\approx 0.24-0.34$, is about $200 \mathrm{mV}$ lower compared to the value in neat water. This is remarkable if one considers that in order to promote such changes at a constant rate constant, the concentration of a reactant or product has to be modified by more than three orders of magnitude.

Unlike for molecular catalysts, the mechanistic details about the processes happening at the surface of an oxide are not fully understood. Especially, there is no consensus about whether the water oxidation at the $\mathrm{IrO}_{2}$ proceeds by a monomolecular or bimolecular pathway. ${ }^{[12 b]}$ Nevertheless, it is universally accepted that $\operatorname{Ir}(\mathrm{III})-\mathrm{OH}_{2}$ centers are oxidized to $\operatorname{Ir}(\mathrm{IV})-\mathrm{OH}$ followed by a partial oxidation to $\operatorname{Ir}(\mathrm{V})=\mathrm{O}$ (Figure 4). The latter species, which possess a radical character (Figure 4), can either react with a $\mathrm{Ir}(\mathrm{IV})-\mathrm{OH}$ center or with a water molecule to produce $\mathrm{O}_{2}$. In both cases, a low-bonded system is beneficial for the overall water oxidation process. In the former case, lowbonded water is expected to regenerate the catalyst more rapidly once the oxygen evolution takes place. On the other hand, if the reaction takes place by a single-site mechanism, a "less

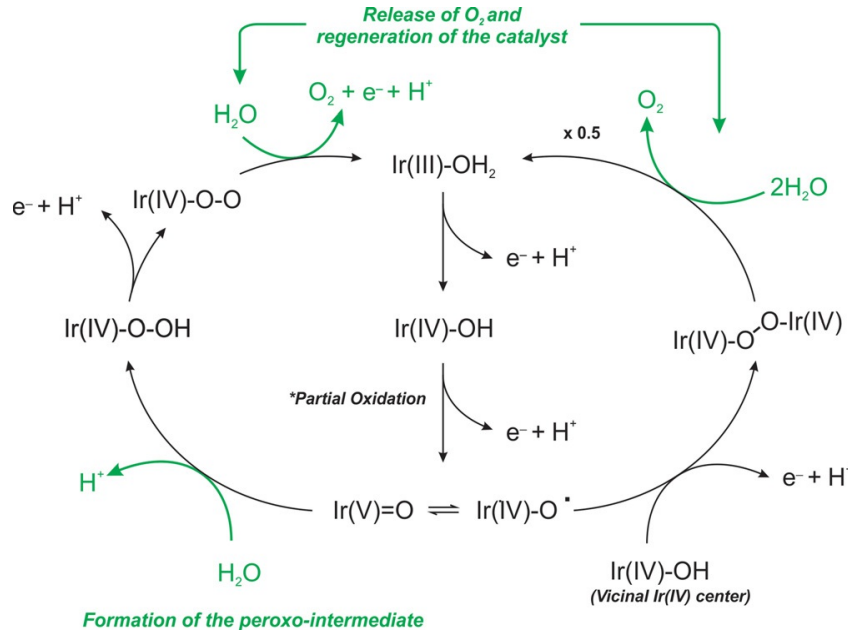

Figure 4. Simplified version of the mechanism for the WOR with IrOx. *Only a fraction of the $\operatorname{Ir}(\mathrm{IV})$ sites undergo oxidation to $\operatorname{Ir}(\mathrm{V})$ species in this step.

protected water molecule" would lead to higher rates in the formation of peroxo-intermediates and regeneration of the catalyst during the oxygen evolution step. In both cases a kinetic effect can explain the experimental results. A simplified scheme showing the two possible mechanisms for WOR as well as the steps where the low bonded water plays a fundamental role is shown in Figure 4. This scheme is based on the mechanism proposed by Crabtree et al. ${ }^{[13]}$ for the oxidation of water catalyzed by organometallic Iridium complexes and the electrochemistry of highly hydrated iridium oxide films (HIROFs). ${ }^{[12,14]}$

All in all, the layer-by-layer methodology presented herein is demonstrated as a highly flexible platform to investigate the electrocatalytic reactivity of various electrode designs, which can incorporate a particular catalyst for a specific process of interest. Specifically, we show that this methodology represents a convenient strategy to evaluate changes in the reactivity of water upon incorporation of a structure breaker co-solvent. This study highlights that a tipping point exists where the kinetic barriers to water oxidation begin to lower when $\mathrm{XH}_{2} \mathrm{O} \leq$ 0.6 in water/ACN mixtures. This finding correlates very well with our previous findings that the kinetics of the WOR in water/ACN mixtures is enhanced with decreasing $X_{2} \mathrm{O}$ in the region $0.4 \leq X \mathrm{H}_{2} \mathrm{O} \leq 0.8$. Thus, while the majority of studies in the literature focus on improving the kinetic efficiency of the WOR through advanced water oxidation catalyst design, we highlight that serious improvements to both may be attained though the incorporation of additives to neat water. In this respect, future work will involve the introduction of molecules capable of modifying the structure of water, such as chaotropic and cosmotropic agents. Furthermore, the evaluation via electrochemistry on $\mathrm{IrO}_{2} / \mathrm{FTO}$ surfaces could be a valuable tool to study the Hofmeister series from the point of view of reactivity. 


\section{Experimental Section}

\section{Chemicals}

All chemicals were used as received without further purification. Potassium hexachloroiridate(IV) $\left(\mathrm{K}_{2} \mid \mathrm{rCl}_{6}, 99.99 \%\right)$, trisodium citrate dihydrate $(\geq 99.0 \%)$, poly(diallydimethylammonium chloride) (PDDA, 20\%, $M_{\mathrm{w}}$ 200000-350000), hexaammineruthenium(III) chloride $\left(\mathrm{Ru}\left(\mathrm{NH}_{3}\right)_{6} \mathrm{Cl}_{3}, 98 \%\right)$, HPLC-grade acetonitrile ( $\left.\mathrm{ACN}, \geq 99.0 \%\right)$ and perchloric acid $\left(\mathrm{HClO}_{4}, 70 \%\right)$ were purchased from Aldrich. The water/ACN mixtures were prepared using HPLC grade ACN and ul-

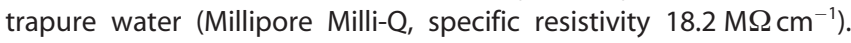
Pure $\mathrm{O}_{2}$ (medical) cylinders were purchased from Carbagas.

\section{Instrumentation}

Electrochemical experiments were carried out under aerobic conditions at an ambient temperature $\left(23 \pm 2^{\circ} \mathrm{C}\right)$ using a PGSTAT 30 potentiostat (Metrohm, CH). A typical three-electrode configuration was used for all cyclic voltammetry experiments. The working electrodes were FTO slides modified (15 $\Omega \mathrm{sq}^{-1}, 2.2 \mathrm{~mm}$ thickness, Solaronix) with eight bilayers of $\mathrm{IrO}_{2} / \mathrm{PDDA}$. The $\mathrm{IrO}_{2} \mathrm{NPs}$ were synthesized and characterized as discussed previously. ${ }^{[8,10]}$ The catalytic electrodes were prepared using a layer-by-layer (LbL) methodology, sequentially depositing negatively charge citrate stabilized $\mathrm{IrO}_{2} \mathrm{NPs}$ and the cationic PDDA polymer. This methodology is described in detail in the Supporting Information and is schematically shown in Figure 1. Briefly, clean FTO slides were immersed in a solution of a positively charged polymer (PDDA), rinsed and immersed in a solution of negatively charged citrate-stabilized $\mathrm{IrO}_{2} \mathrm{NPs}$. By repeating this procedure a multilayer of catalyst was obtained. A detailed study of the WOR at these FTO-modified electrodes, in terms of electrode stability, effect of $\mathrm{pH}$, number of bilayers, and so forth, is reported elsewhere. ${ }^{[10]}$ The counter and reference electrodes in solution were a platinum wire and a $\mathrm{Ag} / \mathrm{AgCl}$ electrode, respectively.

\section{Acknowledgements}

Financial support is acknowledged from the project PolSwiss PSPB-35/2010. This publication has emanated from research by M.D.S. supported in part by a research grant from Science Foundation Ireland (SFI) under Grant Number 13/SIRG/2137.

Keywords: iridium oxide • layer-by-layer assembly nanoparticles $\cdot$ water oxidation $\cdot$ water/acetonitrile mixtures
[1] a) J. Barber, Chem. Soc. Rev. 2009, 38, 185-196; b) E. S. Andreiadis, M. Chavarot-Kerlidou, M. Fontecave, V. Artero, Photochem. Photobiol. 2011, $87,946-964$.

[2] a) H. Yamazaki, A. Shouji, M. Kajita, M. Yagi, Coord. Chem. Rev. 2010, 254, 2483-2491; b) D. M. Robinson, Y. B. Go, M. Greenblatt, G. C. Dismukes, J. Am. Chem. Soc. 2010, 132, 11467-11469; c) C. Sens, I. Romero, M. Rodríguez, A. Llobet, T. Parella, J. Benet-Buchholz, J. Am. Chem. Soc. 2004, 126, 7798-7799; d) R. Zong, R. P. Thummel, J. Am. Chem. Soc. 2005, 127, 12802-12803; e) J. J. Concepcion, J. W. Jurss, J. L. Templeton, T. J. Meyer, J. Am. Chem. Soc. 2008, 130, 16462-16463; f) M. D. Kärkäs, O. Verho, E. V. Johnston, B. Åkermark, Chem. Rev. 2014, 114, 11863-12001; g) J. D. Blakemore, R. H. Crabtree, G. W. Brudvig, Chem. Rev. 2015, 115, 12974-13005.

[3] N. Danilovic, R. Subbaraman, D. Strmcnik, A. P. Paulikas, D. Myers, V. R. Stamenkovic, N. M. Markovic, Electrocatalysis 2012, 3, 221 - 229.

[4] a) H. Deng, P. Peljo, T. J. Stockmann, L. Qiao, T. Vainikka, K. Kontturi, M. Opallo, H. H. Girault, Chem. Commun. 2014, 50, 5554-5557; b) H. Deng, T. J. Stockmann, P. Peljo, M. Opallo, H. H. Girault, J. Electroanal. Chem. 2014, 731, 28-35.

[5] Z. Chen, J. J. Concepcion, H. Luo, J. F. Hull, A. Paul, T. J. Meyer, J. Am. Chem. Soc. 2010, 132, 17670-17673.

[6] M. K. Coggins, M.-T. Zhang, A. K. Vannucci, C. J. Dares, T. J. Meyer, J. Am. Chem. Soc. 2014, 136, $5531-5534$.

[7] a) C. Zhao, A. M. Bond, J. Am. Chem. Soc. 2009, 131, 4279-4287; b) G. Bernardini, A. G. Wedd, C. Zhao, A. M. Bond, Proc. Natl. Acad. Sci. USA 2012, 109, $11552-11557$.

[8] J. C. Hidalgo-Acosta, M. A. Mendez, M. D. Scanlon, H. Vrubel, V. Amstutz, W. Adamiak, M. Opallo, H. H. Girault, Chem. Sci. 2015, 6, 1761-1769.

[9] a) C. Moreau, G. Douhéret, Thermochim. Acta 1975, 13, 385-392; b) D. Jamroz, J. Stangret, J. Lindgren, J. Am. Chem. Soc. 1993, 115, 61656168 ; c) H. Kovacs, A. Laaksonen, J. Am. Chem. Soc. 1991, 113, $5596-$ 5605; d) J. E. Bertie, Z. Lan, J. Phys. Chem. B 1997, 101, 4111-4119; e) T. Takamuku, M. Tabata, A. Yamaguchi, J. Nishimoto, M. Kumamoto, H. Wakita, T. Yamaguchi, J. Phys. Chem. B 1998, 102, 8880-8888.

[10] J. C. Hidalgo-Acosta, M. D. Scanlon, M. A. Mendez, V. Amstutz, H. Vrubel, M. Opallo, H. H. Girault, Phys. Chem. Chem. Phys. 2016, 18, 9295-9304.

[11] a) B. Su, I. Hatay, F. Li, R. Partovi-Nia, M. A. Méndez, Z. Samec, M. Ersoz, H. H. Girault, J. Electroanal. Chem. 2010, 639, 102-108; b) M. A. Méndez, R. Partovi-Nia, I. Hatay, B. Su, P. Ge, A. Olaya, N. Younan, M. Hojeij, H. H. Girault, Phys. Chem. Chem. Phys. 2010, 12, 15163-15171.

[12] a) P. Steegstra, E. Ahlberg, Electrochim. Acta 2012, 76, 26-33; b) P. Steegstra, M. Busch, I. Panas, E. Ahlberg, J. Phys. Chem. C 2013, 117, $20975-20981$.

[13] a) J. D. Blakemore, N. D. Schley, D. Balcells, J. F. Hull, G. W. Olack, C. D. Incarvito, O. Eisenstein, G. W. Brudvig, R. H. Crabtree, J. Am. Chem. Soc. 2010, 132, 16017-16029; b) J. M. Thomsen, D. L. Huang, R. H. Crabtree, G. W. Brudvig, Dalton Trans. 2015, 44, $12452-12472$.

[14] a) D. N. Buckley, L. D. Burke, J. Chem. Soc. Faraday Trans. 1 1975, 71, 1447-1459; b) D. N. Buckley, L. D. Burke, J. Chem. Soc. Faraday Trans. 1 1976, 72, 2431-2440; c) D. N. Buckley, L. D. Burke, J. K. Mulcahy, J. Chem. Soc. Faraday Trans. 1 1976, 72, 1896-1902.

Manuscript received: April 12, 2016 Accepted Article published: June 2, 2016

Final Article published: June 17, 2016 